Journal of Applied Pharmaceutical Science Vol. 7 (07), pp. 103-110, July, 2017

Available online at http://www.japsonline.com

DOI: $10.7324 /$ JAPS.2017.70716

ISSN 2231-3354 (cc) EY-NC-SA

\title{
Discovering COX-2 Inhibitors from Flavonoids and Diterpenoids
}

\author{
Jutti Levita ${ }^{1 *}$, Muhammad Riza Rositama ${ }^{1}$, Nazura Alias ${ }^{1}$, Nurul Khalida ${ }^{1}$, Nyi Mekar Saptarini ${ }^{2}$, Sandra Megantara ${ }^{2}$ \\ ${ }^{1}$ Department of Pharmacology and Clinical Pharmacy Faculty of Pharmacy Universitas Padjadjaran Jl. Raya Bandung-Sumedang, Jatinangor West Java, \\ Indonesia. ${ }^{2}$ Department of Pharmaceutical Analysis and Medicinal Chemistry Faculty of Pharmacy Universitas Padjadjaran Jl. Raya Bandung-Sumedang, \\ Jatinangor West Java, Indonesia.
}

\begin{tabular}{l} 
ARTICLE INFO \\
\hline Article history: \\
Received on: $21 / 11 / 2016$ \\
Accepted on: 06/01/2017 \\
Available online: $30 / 07 / 2017$ \\
\hline Key words: \\
Anti-inflammatory, \\
arachidonic acid, \\
cyclooxygenase, NSAIDs, \\
binding mode, NSAIDs, \\
PGH, prostaglandin.
\end{tabular}

\begin{abstract}
Cyclooxygenase is the enzyme that catalyzes the biosynthesis of prostaglandins from its substrate, arachidonic acid (AA). The reactions involve two steps which are (1) the oxidation of AA to the hydroperoxyendoperoxide $\mathrm{PGG}_{2}$, followed by (2) its subsequent reduction to the hydroxyl endoperoxide $\mathrm{PGH}_{2}$. Selective $\mathrm{COX}-2$ inhibitors do not bind to Arg120, an amino acid residue used by AA and by the nonselective NSAIDs, all of which are carboxylic acids. In this work we studied the interaction of 54 compounds against COX enzymes for antiinflammatory discovery using molecular docking simulation. Docking simulation for each compound was repeated 100x using Linux script command for AutoDockVina embedded in MGLTools v.1.5.6. Discovery Studio v.2.5.5 was employed to predict the volume of both COX binding pockets. 21 compounds were selected according to their best scoring values and were calculated their selectivity index (cSI). Selective COX-2 inhibitors, respectively, are (1) 3,19-O-diacetylandrographolide; (2) 2-((1R,4aS,5R,6R,8aS)-6-hydroxy-5(hydroxymethyl)-5,8a-dimethyl-2 methylene decahydronaphthalen-1-yl)-1-(2-oxo-2,5-dihydrofuran-3-yl) ethyl 4-methylbenzoate; and (3)12,13-dihydroandrographolide. Preferential COX-2 inhibitorsare (1) coronarin D; (2) 19-O-acetylhydroandrographolide; (3) p-methoxycinnamic acid; (4) kaempferide. The rest of the ligands are categorized as non-selective inhibitors.
\end{abstract}

\section{INTRODUCTION}

Cyclooxygenases are membrane -associated hemecontaining homodimers enzymes that catalyze the biosynthesis of prostaglandins from their substrate, arachidonic acid (AA). The reactions involve two steps which are (1) the oxidation of AA to the hydroperoxyendoperoxide $\mathrm{PGG}_{2}$, followed by (2) its subsequent reduction to the hydroxyl endoperoxide $\mathrm{PGH}_{2}$ (Vane et al, 1998; Vecchio et al, 2010). Selective COX-2 inhibitors do not bind to Arg120, an amino acid residue used by AA and by the nonselective NSAIDs, all of which are carboxylic acids (Mancini et al, 1995). The mechanism of inhibition of COX activity by acetosal and NSAIDs was first described by Vane in

* Corresponding Author

Jutti Levita, Department of Pharmacology and Clinical Pharmacy

Faculty of Pharmacy Universitas Padjadjaran Jl. Raya Bandung-

Sumedang, Jatinangor West Java, Indonesia.

Email: jutti.levita@unpad.ac.id
1971 (Vane, 1971). Although AA is the preferred substrate, other fatty acids are oxygenated by these enzymes with varying efficiencies. The interactions identified between the enzyme and the fatty acids when bound to COX-1 are conserved in COX-2 structures, with the only difference is the lack of interaction of the carboxylate of AA and eicosapentaenoic acid (EPA) with Arg-120. Leu-531 exhibits a different side chain conformation when the nonproductive and productive binding modes of AA are compared. It was speculated that the mobility of the Leu-531 side chain increased the volume available at the opening of the cyclooxygenase channel and contributes to the observed ability of COX-2 to oxygenate a broad spectrum of fatty acid and fatty ester substrates (Vecchio et al, 2010). However, NSAIDs cause gastrointestinal adverse effects, mainly because of their inhibition of the constitutive isoform of COX. Since selective COX-2 inhibitors fail to inhibit constitutive COX-1 isoform, they have no gastrointestinal adverse effects (Dilber et al, 2010). 
Selective COX-2 inhibitors, e.g. coxib drugs such as rofecoxib $\left(\right.$ Vioxx $\left.^{\circledR}\right)$ and valdecoxib (Bextra $\left.{ }^{\circledR}\right)$,were withdrawn from the market in 2004 and 2005, respectively, because of their effects on increased risk of heart attacks and strokes in long term use (Mason et al, 2006). Bioactive compounds, such as flavonoids and diterpenoids, have been proven to show anti-inflammatory activity. While many studies on flavonoids have already been explored, in this work we studied the interaction of 54 diterpenoids against COX enzymes for anti-inflammatory discovery using molecular docking simulation. Plants selected were Andrographis paniculata, Kaempferia galanga L., Hibiscus sabdariffa L., Tripterygium wilfordii Hook, f. (TWHF), and Eunicellane-based diterpenoids (Levita et al., 2010; Lin et al., 2007;

Gonzales et al, 2015).

\section{METHODS}

\section{Protein preparation}

The X-ray crystallographic 3D structures of COX-1 (PDB code: $3 \mathrm{~N} 8 \mathrm{X}$, resolution 2.75 Åcomplexed with nimesulide, crystallized by Sidhu et al, 2010) and COX-2 (PDB code: 5IKR, $2.34 \AA$ complexed with mefenamic acid, crystallized by Orlando and Malkowski, 2016) were downloaded from online Protein Data Bank (Fig.1).Water molecules, ligands, and other hetero atoms were removed from the protein molecule along with the chain $\mathrm{B}, \mathrm{C}$ and D, using Swiss-Pdb Viewer v4.0.4 (Swiss Institute of Bioinformatics, downloaded fromwww.expasy.org).Addition of hydrogen atoms and Kollman charges to the protein was performed using AutoDockVina (Molecular Graphics LaboratoryThe Scripps Research Institute, downloaded from http://autodock.scripps.edu). The binding modes of COX-1 with nimesulide and COX-2 with mefenamic acid were studied using Ligand Explorer Viewer v.4.1.0 (Research Col laboratory for Structural Bioinformatics, embedded onhttp://www.pdb.org/pdb/explore). The binding pockets were calculated their volumes by using bind module in PLANTS 1.2and were visualized using Discovery Studio v.2.5.5 (Fig.2 and 3).

\section{Ligand preparation}

All ligands were generated by using ChemBioDraw Ultra14.0 free trial (downloaded from www.cambridgesoft.com), and were geometry optimized using HyperChem Professional 8.0 by employing MMFF94 forcefield. The ligands were calculated their $\log \mathrm{P}$ and were saved in pdb.file format for further process.

\section{Validation of the docking simulation}

Validation was performed re-docking of the ligand into its origin location for 50x using Linux script command, continued by calculating the SD of the binding energy and Ki. The re-docked ligand was then superimposed with the co-crystallized ligand extracted from the enzyme.

\section{Docking simulation}

Docking simulation for all 54 ligands was repeated 100x using Linux script command for AutoDockVina embedded in
MGL Tools v.1.5.6 at position $x=26.8092 ; y=33.6399 ; z=$ 199.8130 for COX-1 whereas for COX-2was at $x=-16.0647 ; y=$ $41.6941 ; z=25.6819$ (these coordinates are within $10 \AA$ distance centered to the ligand position). These coordinates were calculated by employing bind module in PLANTS 1.2.The default parameters of the automatic settings were used to set the genetic algorithm parameters. The docked conformation which had the highest docking score was selected to analyze the binding mode (Mason et $a l, 2006)$. Nimesulide and celecoxib were used as standards.

\section{RESULT AND DISCUSSION}

To screen the potential of COX inhibitory properties of the selected compounds, all compounds were evaluated through AutoDockV in an in silico molecular docking studies. First, the binding pocket volume of COX-1 and COX-2 was calculated by using bind module in PLANTS 1.2, and the results are 833.125 $\AA^{3}$ and $981.625 \AA^{3}$, respectively (Fig. 1 and 2). Nimesulide, an NSAID, showed two hydrogen bonds (HBs) formation with Arg120 (distance $2.7 \AA$ ) and Leu352 (distance $2.6 \AA$ ) at the opening of cyclooxygenase site of COX-1 (Fig. 1), whereas mefenamic acid formed only one HB with Tyr385 (distance $2.8 \AA$ ) in the cyclooxygenase site of COX-2 (Fig. 2).

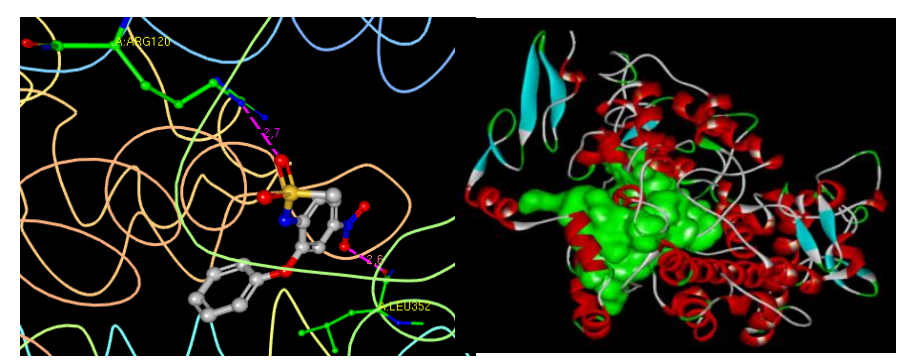

Fig.1. Binding modes of nimesulide in COX-1 (left; PDB code: 3N8X, resolution 2.75A complexed with nimesulide, crystallized by Sidhu et al, 2010) (Sidhu et al, 2010) and the binding pocket of COX-1 visualized in green (right) by using Discovery Studio.

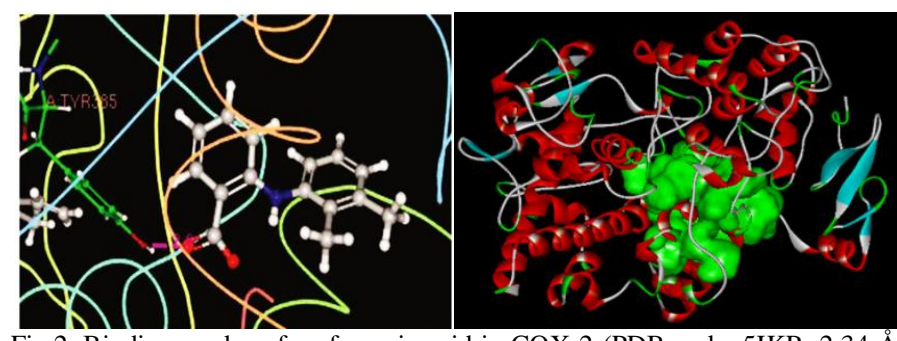

Fig.2. Binding modes of mefenamic acid in COX-2 (PDB code: 5IKR, $2.34 \AA$ complexed with mefenamic acid, crystallized by Orlando and Malkowski, 2016)(Orlando and Malkowski, 2016)and the binding pocket of COX-2 visualized in green (right) by using Discovery Studio

During ligand preparation process, all selected compounds were built and geometry optimized. Their $\log \mathrm{P}$ was calculated and showed in Fig.4 and Table 1. 


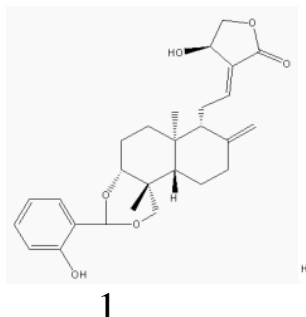

1

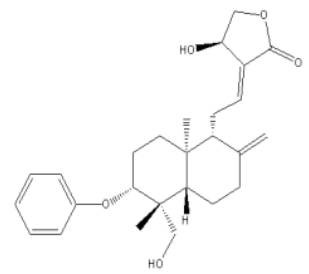

6

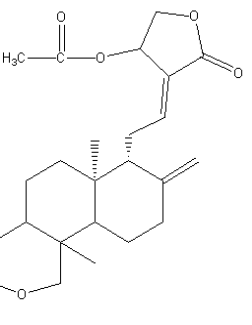

11

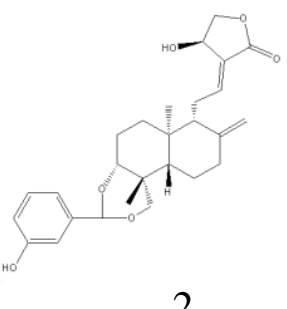

2

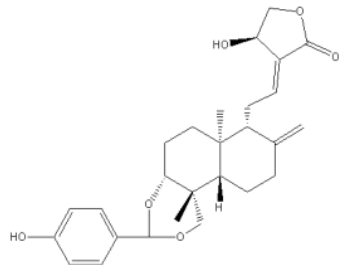

3

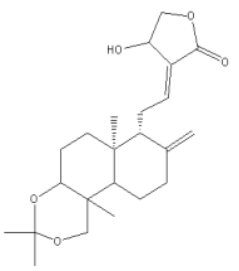

4

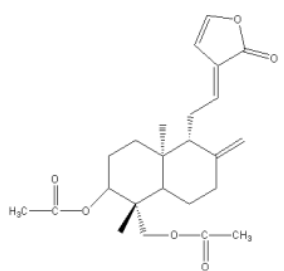

5

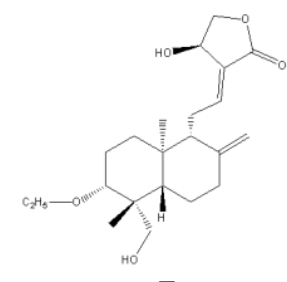

7

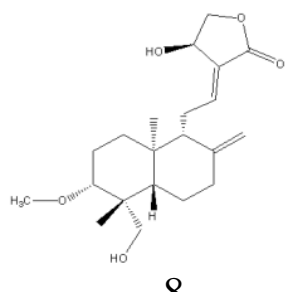

8

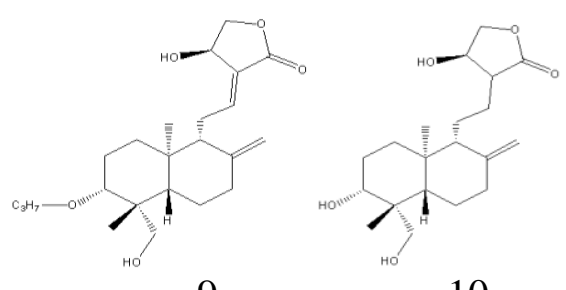

10

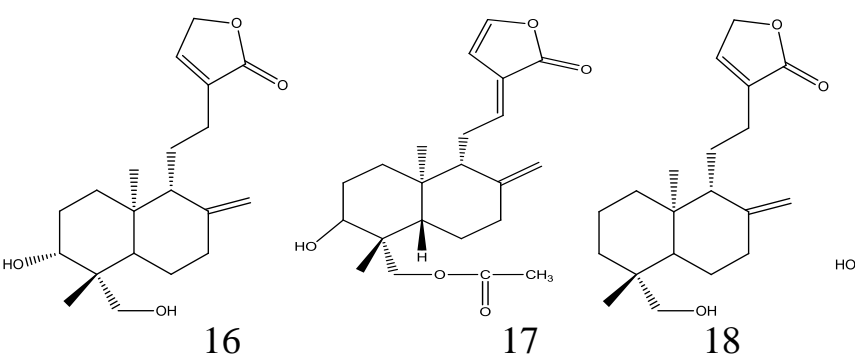

12

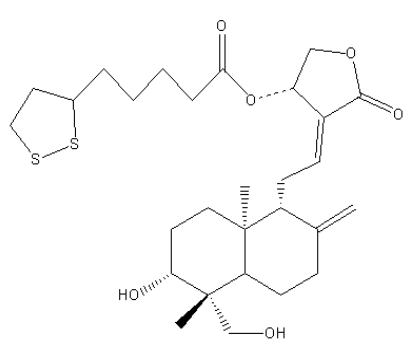

13

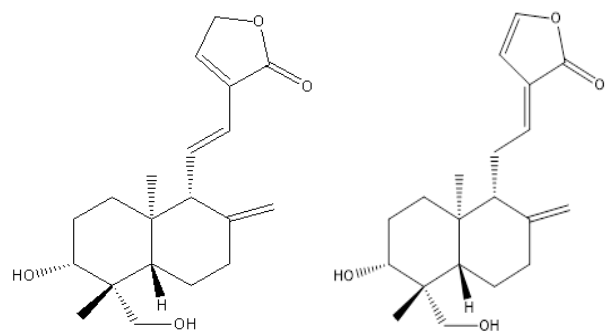

15
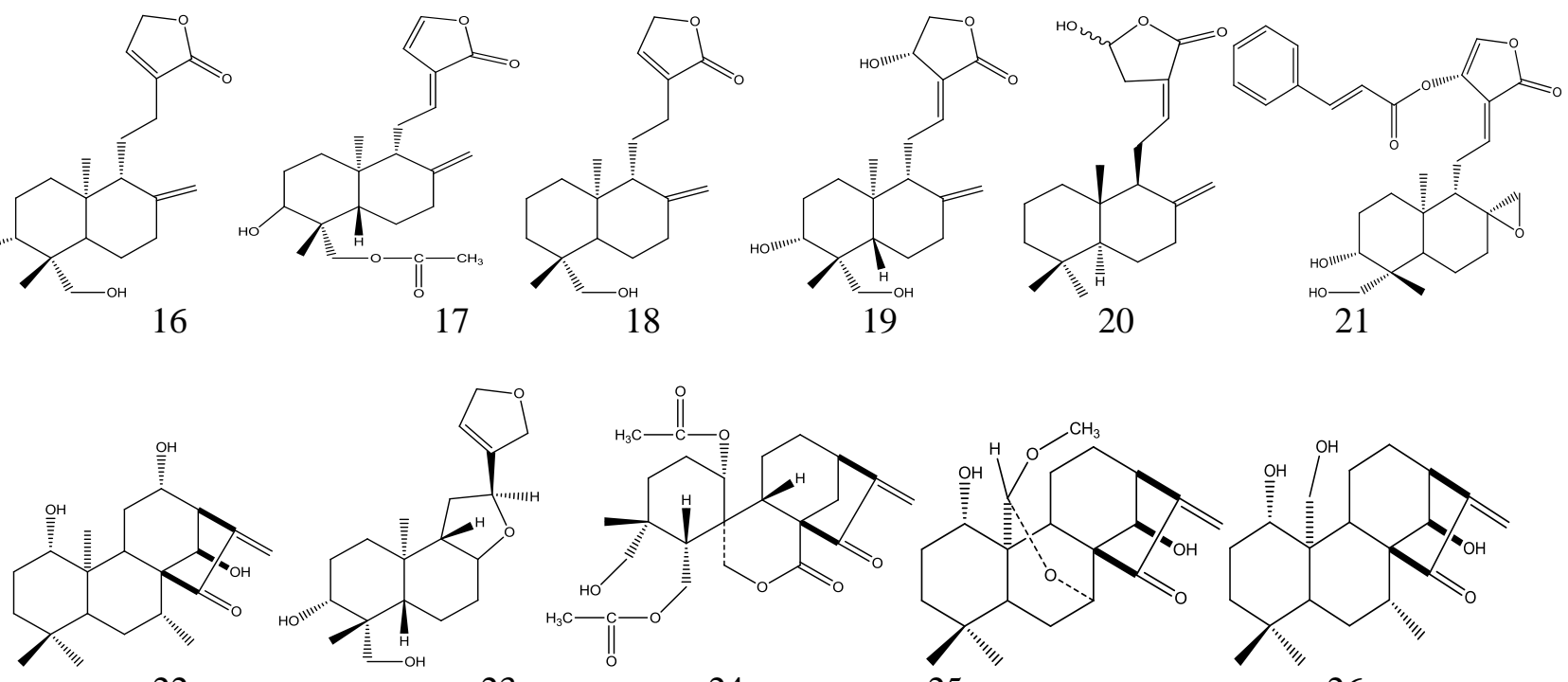

22

23

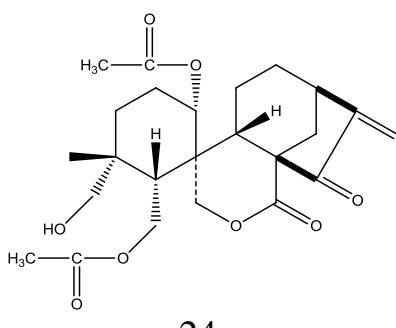

24

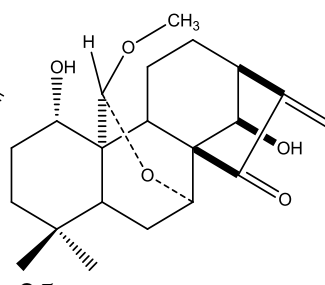

25

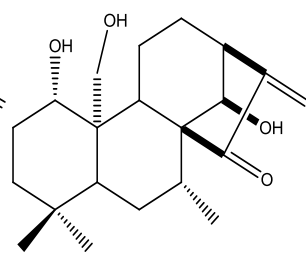

26

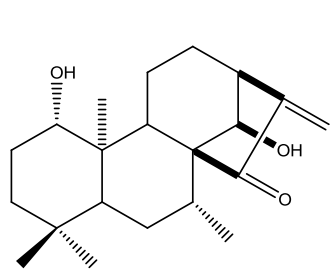

27

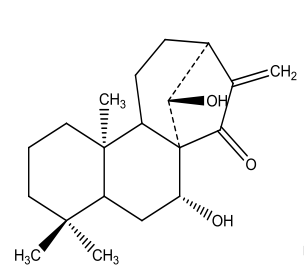

28

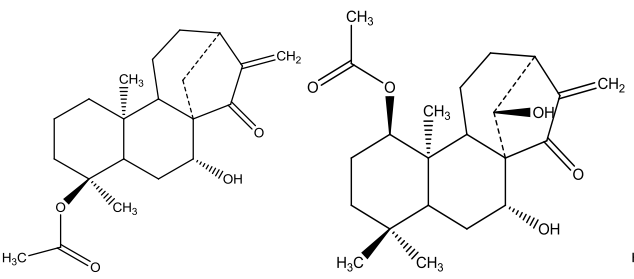

29

30

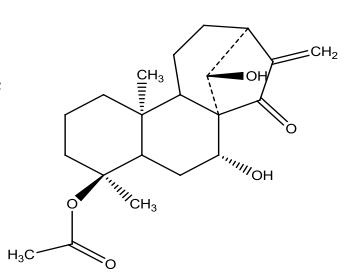


<smiles>C=C(C)O[C@]1(C)CCC[C@]2(C)C3CCC4CC3C(=O)C4(C)[C@H](O)C[C@H]12</smiles>

31

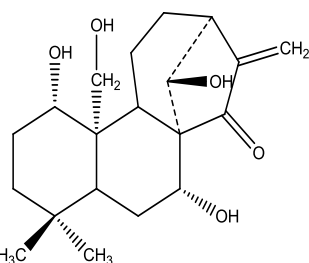

32

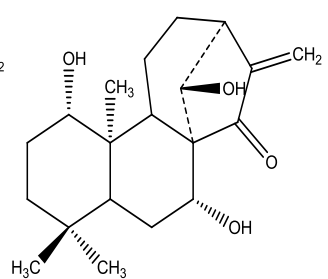

33

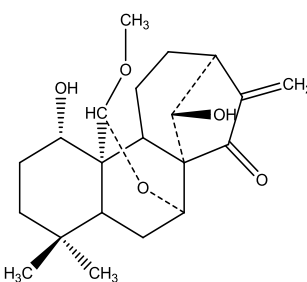

34

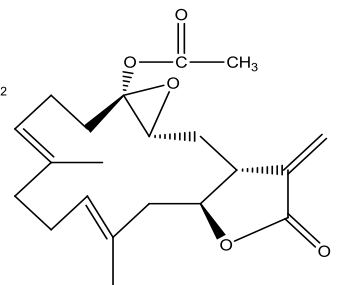

35

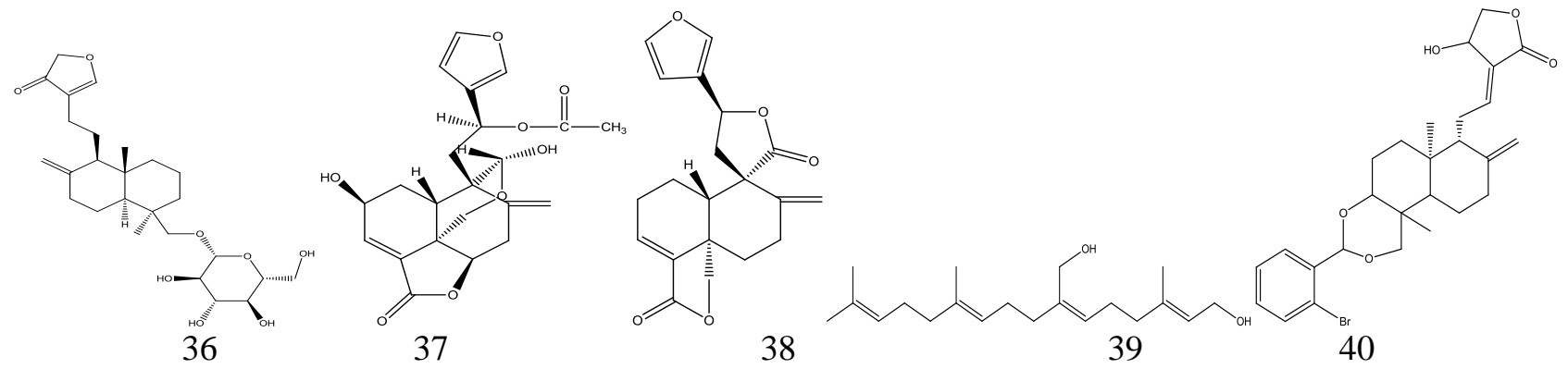

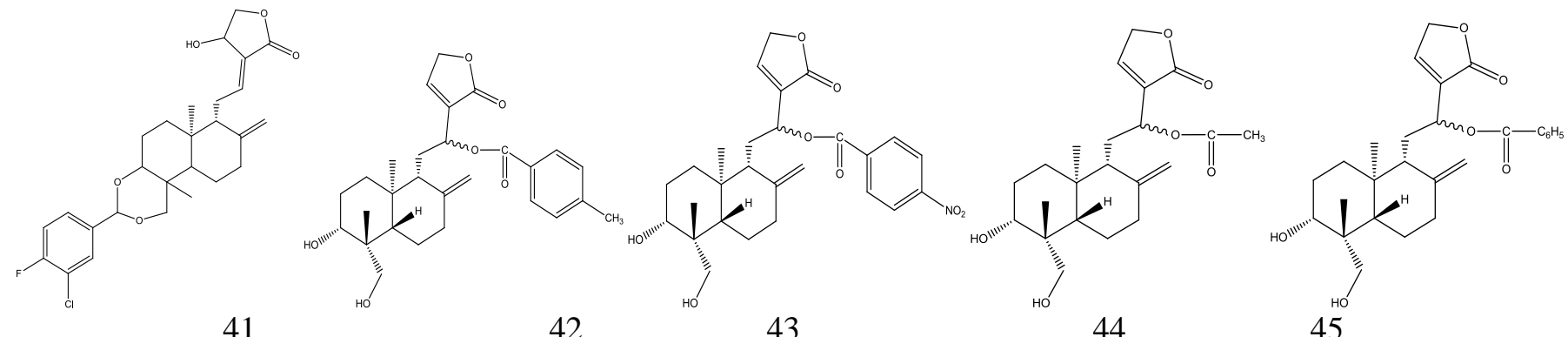

41

42

43

44<smiles>CCOC(=O)/C=C/c1ccc(OC)cc1</smiles>

49

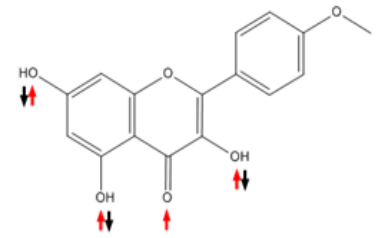

50

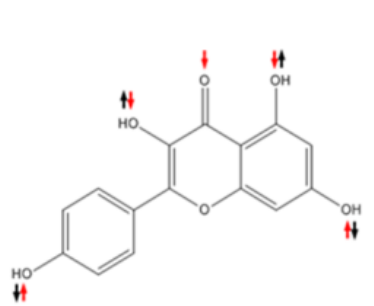

50

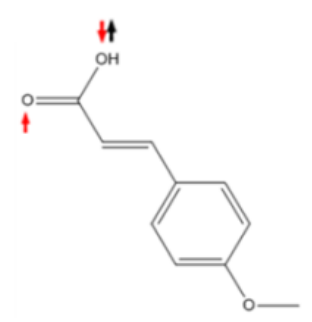

51
48

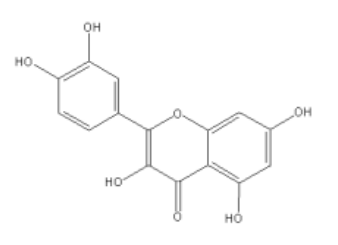

52

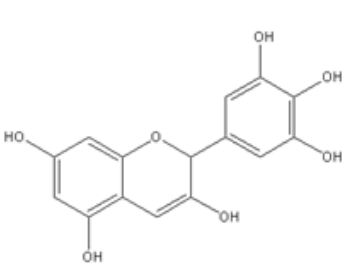

53
54

Fig. 3: 2D structure of the 54 ligands (generated by using ChemBioDraw Ultra 14.0 free trial downloaded from www.cambridgesoft.com). 

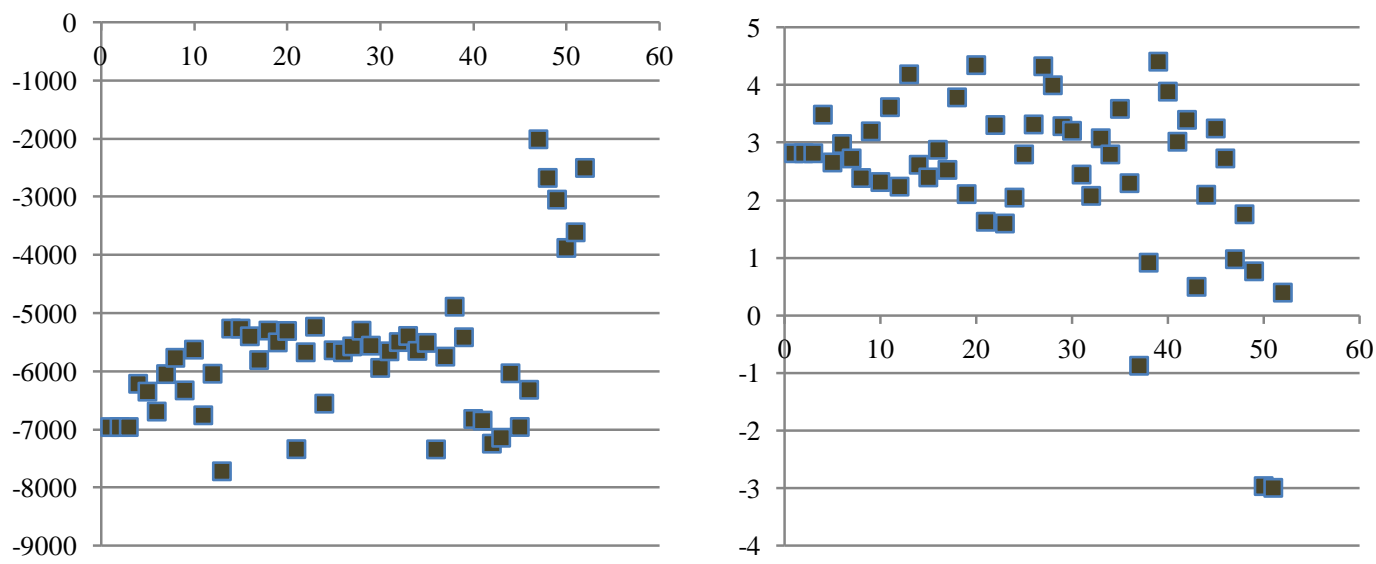

Fig. 4: The distribution of energy values after geometry optimization (left) and $\log P$ (right) of the ligands (listed in Fig. 3).
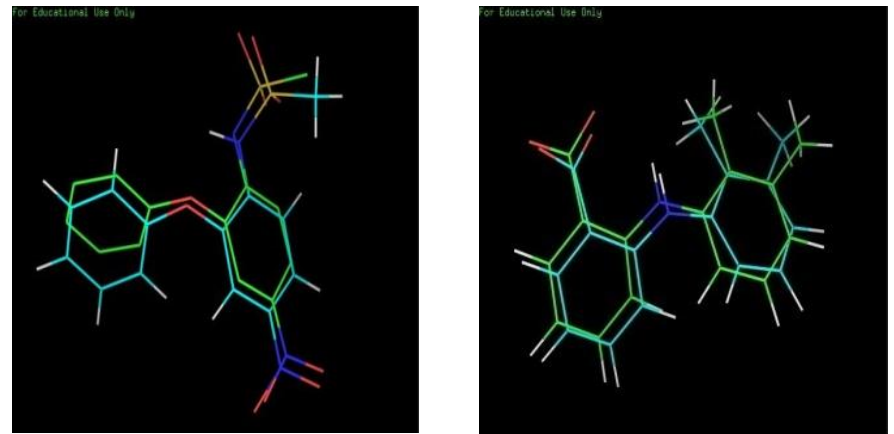

Fig.5. Superimposed of nimesulides (left; RMSD 0.535) and mefenamic acids (right; RMSD 0.544)
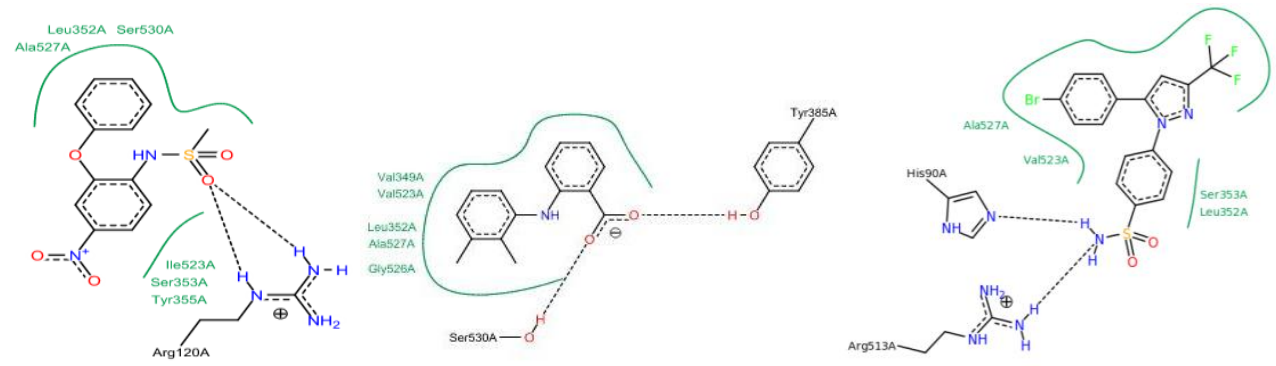

Fig. 6: PoseView 2D visualization of the binding modes of nimesulide with COX-1 (left), metenamic acid (center)and sc s૪ (right) with COX-2.

The distribution of energy values after geometry optimization (Fig.4 left) and log P (Fig.4 right) of the ligands (listed in Fig.3) was provided in Fig.4.It could be seen that 88.46\% of the ligands used in this work showed low energy values, whereas the $\log \mathrm{P}$ of $94.23 \%$ of the ligands was positive, which indicates hydrophobicity. The highest hydrophobicity belongs to plaunotol due to its long carbon chain, whereas the most hydrophilic compound is kaempferol, which has four hydroxyl groups. Validation was performed re-docking the ligand into its origin location for $50 \mathrm{x}$, continued by calculating the SD of the binding energy and $\mathrm{Ki}$. The resulted binding energy value is -7.845 $\pm 1.02 \mathrm{kcal} / \mathrm{mol}$, whereas the $\mathrm{Ki}$ is $0.069 \pm 0.076(n=50)$. The redocked ligand was then superimposed with the co-crystallized ligand extracted from the enzyme (Fig.5). Amino acid residues in the cyclooxygenase site of COX-1 areHis90, Met113, Val116, Arg120, Tyr348, Val349, Leu352, Ser353, Tyr355, Leu359, Phe381, Leu384, Tyr385, Trp387, Ile517, Phe518, Met522,
Ile523, Gly526, Ala527, Ser530, Leu531; while those of COX-2 are Arg120, Tyr348, Val349, Leu359, Leu352, Ser353, Tyr355, Leu384, Tyr385, Trp387, Met522, Val523, Gly526, Ala527, Ser530, Leu531. These docking data is in accordance with reported data on prodigiosin and cycloprodigiosin reported by Krishna et al (2013) where amino acid residues such as His90, Arg120, Gln192, Val349, Leu352, Ser353, Tyr355, Leu359, Tyr385, Trp387, Arg513, Ala516, Phe518, Val523, Gly526, Ala527, Leu531 associated with A chain of COX-2 protein were involved for protein-ligand complementarily activity(Krishnaet al, 2013). COX-2 active site possess three important regions: (1) a hydrophobic pocket (contains Tyr385, Trp387, Phe518, Ala201, Tyr248 and Leu352); (2) a hydrophilic region (contains Arg120, Glu524 and Tyr355) at the entrance of the active site; (3) a side pocket with the presence of His90, Arg513 and Val523 (D'Mello et al, 2011). PoseView 2D visualization of the standards with COX-1 and COX-2 were provided in Fig.6. 
Nimesulide (Fig.6 left) interacts with Arg120, an amino acid residue at the opening channel of cyclooxygenase site of COX-1. The sulfoxide moiety of nimesulide acts as hydrogen bond acceptor (HBA) to the amines of Arg120, which, in this interaction, are the donors (HBD). This type of interaction is similar with that of flurbiprofen (Sindhu et al, 2010), methyl ester flurbiprofen (Selinsky et al, 2001), (R)-naproxen (Duggan et al, 2011). Mefenamic acid, on the other hand, interacts with Tyr385 in the cyclooxygenase site of COX-2, as showed by diclofenac (Sidhu et al, 2010). Aselective COX-2 inhibitor, SC58 showed specific interaction with Arg513 (Kurumbail et al, 1996).

Molecular docking simulations of selected compounds in COX-1which showed interaction with Arg120 and/or Tyr355and in COX-2 which showed interaction with Tyr385 and/or Ser530 were provided in Fig.7 and Fig.8, respectively.

We compared our work with that of D'Mello who studied the modeling of flavonoids for COX inhibitors. They mentioned that chrysin and apigenin's5-hydroxyl interacted with Tyr355 forming a H-bond, while 4'-OH on the B-ring of apigenin formed an additional H-bond with Tyr385.Morin and kaempferol indicated an interaction with Arg120 and Tyr355 (D'Mello et al, 2011). Previous work of Mancini et al. (1995) concluded that there was biochemical evidence of the importance of the Arg1 20 residue in COX-1 for interaction with arachidonic acid and NSAIDs containing a free carboxylic acid moiety(Mancini et al, 1995). Furthermore, a comparison was done with the work of Dash et al (2015) who discovered that salviifosides A of Alangium salvifolium was found to having three hydrogen bondings with Tyr355, Gln192, and Val523(Dash et al, 2015).

The $\mathrm{Ki}$ values of the ligands against $\mathrm{COX}-1$ and $\mathrm{COX}-2$ could be seen in Fig. 9.

Red squares in Fig.9 indicate the standards (nimesulide, acetosal, and celecoxib in COX-1; mefenamic acid, acetosal, and celecoxib in $\mathrm{COX}-2$ ). In these diagrams, ligands which $\mathrm{Ki}$ values higher than $1000 \mu \mathrm{M}$ were excluded. Celecoxib, a selective COX2 inhibitor showed high $\mathrm{Ki}$ value against COX-1 (773.16 $\mu \mathrm{M})$, whilst the $\mathrm{Ki}$ of acetosal, nimesulide, and mefenamic acid against both isoforms are not significantly different.

According to Nunthanavanit and Samee (2011), the inhibition constant $(\mathrm{Ki})$ could be used to estimate the calculated selectivity index (cSI, the ratio of COX-2 Ki to COX-1 Ki of each complex), which are classified as non-selective (cSI> 1), preferential COX-2 $(0.1<\mathrm{cSI}<1.0)$, and selective inhibitors $(\mathrm{cSI}<0.1)$, respectively (Nunthanavanit and Samee, 2011). The cSIof the ligands was further calculated. The result is showed in Table 1.
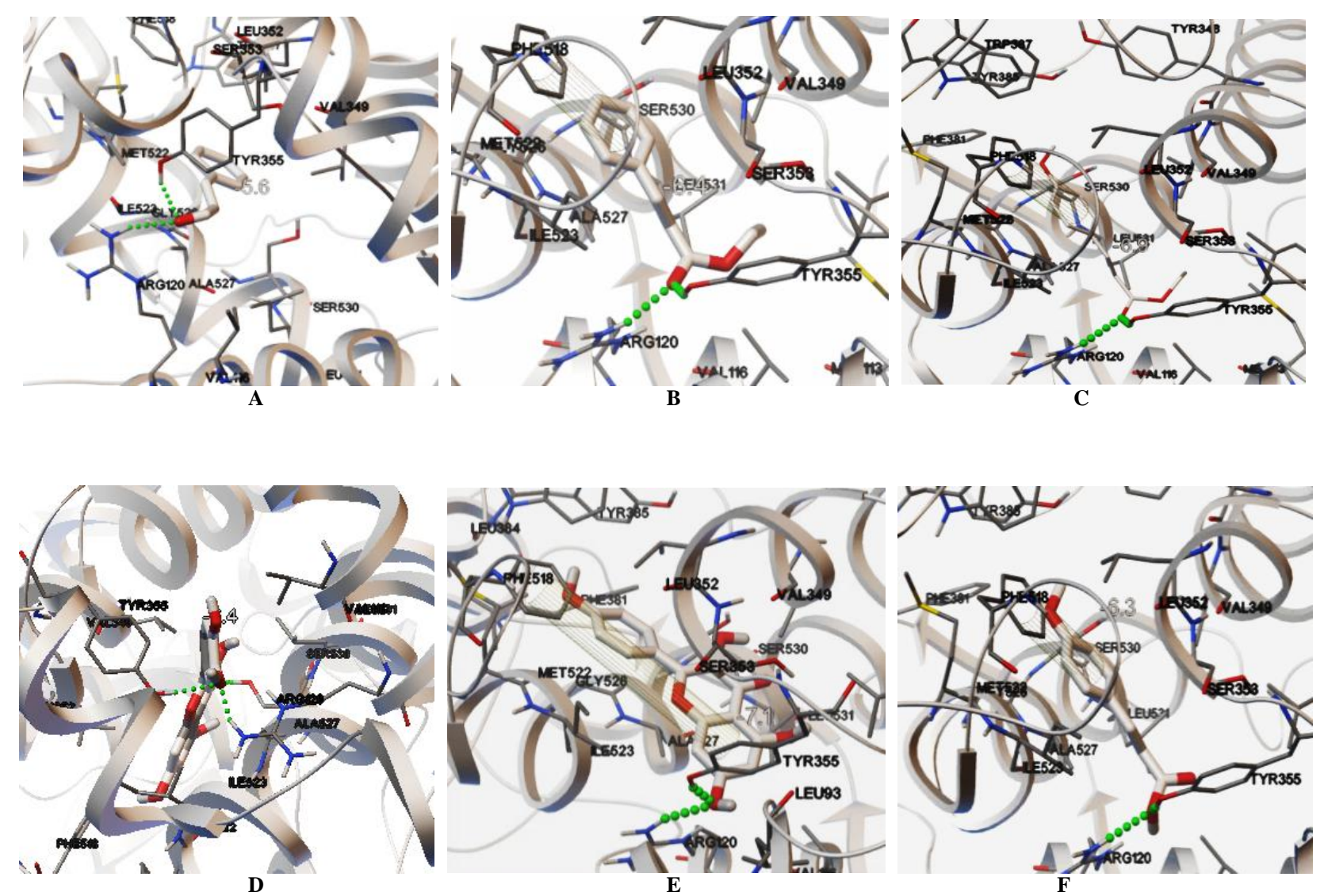

Fig. 7. The binding modes of (a) cinnamaldehyde; (b) ethyl cinnamate; (c) ethyl-p-methoxycinnamate; (d) quercetin; (e) kaempferol; (f) p-methoxycinnamic acid, in COX-1 


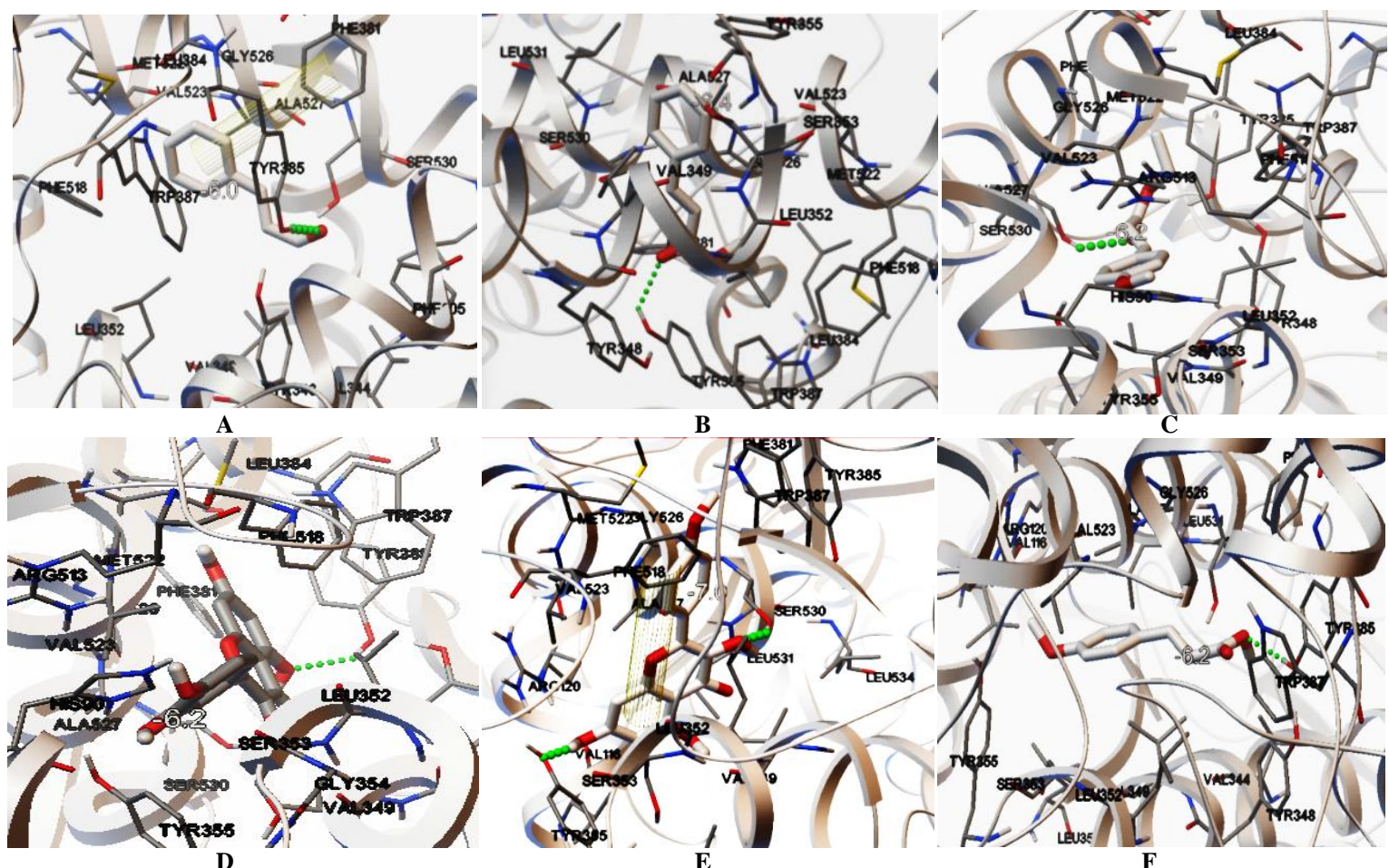

Fig. 8: The binding modes of (a) cinnamaldehyde; (b) ethyl cinnamate; (c) ethyl-p-methoxycinnamate; (d) quercetin; (e) kaempferol; (f) p-methoxycinnamic acid, in COX-2
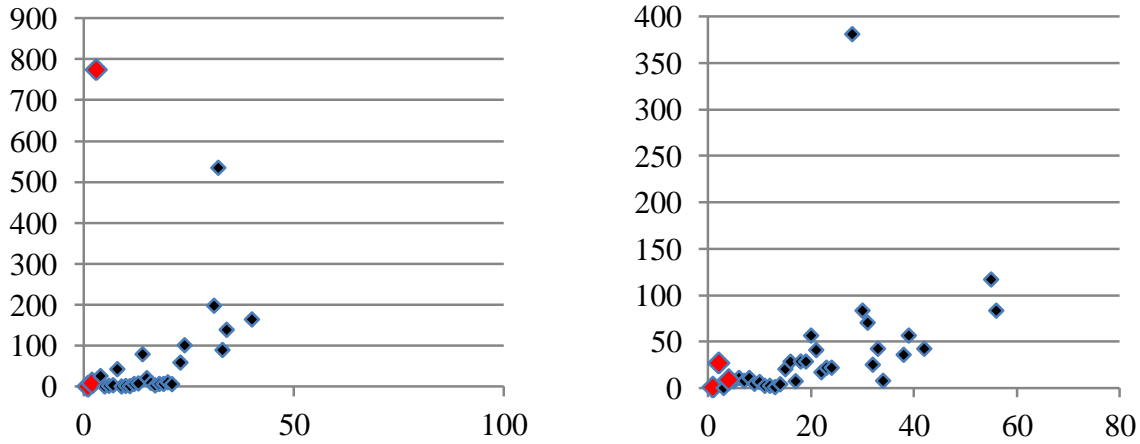

Fig. 9: Scatter diagram of Ki valuesof the ligands(listed in Fig.3) against COX-1 (left) and COX-2 (right)

Table 1 showed that flavonoids and diterpenoids might play important role in interacting with COX enzymes. The selected compounds (cinnamaldehyde, ethyl cinnamate, ethyl-p-methoxy cinnamate, quercetin, kaempferol, and p-methoxy cinnamic acid) show interaction with Arg120 and/or Tyr355 in COX-1, which is similar with that of nonselective NSAIDs and other flavonoids. In COX-2 the same compounds showed interaction with Tyr385 and/or Ser530. Based on the selectivity index calculation (cSI), only a few of the flavonoids and diterpenoids are categorized as selective COX-2 inhibitors.

According to Wong et al (1997), mutations of residues of COX-1: His513 to Arg513 and Ile523 to Val 523 in COX-2, could strongly increase sensitivity to selective COX-2 inhibition and restore time-dependent inhibition. They also suggested that the corresponding Arg499 and Val509 residues of COX-2 are essential determinants in differentiating between the interaction of nonselective NSAIDs and selective COX-2 inhibitors and their mechanism of action (Wong et al, 1997).

Rieke and colleagues (1995) stated that the positively charged guanido group of Arg-120 interfered with the binding COX-2 inhibitors including NS398, DuP-697, and SC58125. NS398 did not cause time-dependent inhibition of R120Q hCOX2, whereas DuP-697 and SC58125 were time-dependent inhibitors. They concluded that Arg-120 was important for the timedependent inhibition of hCOX-2 by NS398 but not by DuP-697 or SC58125 (Rieke et al, 1995). 
Table 1: The cSI of the ligands calculated by using Ki values on COX-1 and COX-2.

\begin{tabular}{lc}
\hline \multicolumn{1}{c}{ Name of the ligand } & $\begin{array}{c}\text { cSI (Ki COX- } \\
\text { 2/Ki COX-1) }\end{array}$ \\
\hline Celecoxib & 0.000 \\
3,19-O-diacetylandrographolide & 0.003 \\
2-((1R,4aS,5R,6R,8aS)-6-hydroxy-5-(hydroxymethyl)- & \\
5,8a-dimethyl-2-methylenedecahydronaphthalen-1-yl)- & \\
1-(2-oxo-2,5-dihydrofuran-3-yl)ethyl & 0.019 \\
methylbenzoate & \\
12,13-dihydroandrographolide & \\
Coronarin D & 0.057 \\
19-O-acetylhydroandrographolide & 0.143 \\
2-((1R,4aS,5R,6R,8aS)-6-hydroxy-5-(hydroxymethyl)- & 0.156 \\
5,8a-dimethyl-2-methylenedecahydronaphthalen-1-yl)- & \\
1-(2-oxo-2,5-dihydrofuran-3-yl)ethyl benzoate & 0.287 \\
p-methoxycinnamic acid & \\
Kaempferide & 0.922 \\
Cinnamaldehyde & 0.927 \\
Ethyl $p$-methoxycinnamate & 0.954 \\
Plaunotol & 1.428 \\
Ethyl cinnamate & 1.498 \\
Kaempferol & 1.507 \\
Asetosal & 1.623 \\
Quercetin & 2.583 \\
Delphinidin & 5.512 \\
14-deoxy-14,15-didehydro andrographolide & 7.106 \\
14-deoxy-11,12-didehydroandrographolide & 15.159 \\
Andrograpanin & 20.875 \\
Andrographolide & 35.847 \\
Nimesulide & 39.047 \\
Mefenamic acid & \\
\hline
\end{tabular}

\section{CONCLUSION}

Selective COX-2 inhibitors, respectively, are (1) celecoxib; (2) 3,19-O-diacetylandrographolide; (3) 2((1R,4aS,5R,6R,8aS)-6-hydroxy-5 -(hydroxymethyl)-5,8adimethyl-2methylenedecahydronaphthalen -1-yl)-1-(2-oxo-2,5dihydrofuran-3-yl)ethyl 4-methylbenzoate; and (4)12,13dihydroandrographolide. Preferential COX-2 inhibitors are (1) coronarin D; (2) 19-O-acetylhydroandrographolide; (3) $p$ methoxycinnamic acid; (4) kaempferide. The rest of the ligands are categorized as non-selective inhibitors.

\section{Financial support and sponsorship: Nil.}

Conflict of Interests: There are no conflicts of interest.

\section{REFERENCES}

Dash R, Ahsan MT, Hosen SMZ,Rahman MG, Emran T, Nasir Uddin MM. Evolution of selective COX-2 inhibitor from Alangium salvifolium: an in silico approach. Journal of Applied Pharmaceutical Science, 2015;5: 89-93.

Dilber SP, Dobric SL, Juranic ZD, Markovic BD, Vladimirov SM, Juranic IO. Molecules, 2008; 13: 603-615.

D’Mello P, Gadhwal MK, Joshi U, Shetgiri P. Modeling of COX-2 inhibitory activity of flavonoids. International Journal of Pharmacy and Pharmaceutical Sciences, 2011; 3: 33-40.

Duggan KC, Hermanson DJ, Musee J, Prusakiewicz JJ, Scheib JL, Carter BD, Banerjee S, Oates JA, Marnett LJ. (R)-Profens are substrateselective inhibitors of endocannabinoid oxygenation by COX-2. Natural Chemistry Biology, 2011; 7: 803-809.

Gonzales Y, Torres-Mendoza D, Jones GE, Fernandez PL. Marine diterpenoids as potential antiinflammatory agents. Hindawi Publishing Coeporation Mediators of Inflammation, 2015; 2015: 1-14.
Krishna PS, Vani K, Prasad MR, Samatha B, Bindu NSVSSSLH, Charya MAS, Shetty PR. In-silico molecular docking analysis of prodigiosin and cycloprodigiosin as COX-2 inhibitors. SpringerPlus, 2013;2: 172-178.

Kurumbail RG, Stevens AM, Gierse JK, McDonald JJ, Stegeman RA, Pak JY, Gildehaus D, Miyashiro JM, Penning TD, Seibert K, Isakson PC, Stallings WC. Structural basis for selective inhibition of cyclooxygenase-2 by anti-inflammatory agents.Nature, 1996; 384: 644-648.

Levita J, Nawawi A, Mutholib A, Ibrahim S. Andrographolide inhibits COX-2 expression in human fibroblast cells due to its interaction with arginine and histidine in cyclooxygenase site. Journal of Applied Sciences, 2010;10:1481-1484

Lin Na, Liu C, Xiao C, Jia H, Imada K, Wu H,Ito A. Triptolide, a diterpenoidtriepoxide, suppresses inflammation and cartilage destruction in collagen-induced arthritis mice. Biochemical Pharmacology, 2007; 73: 136146.

Mancini JA,Riendeau D, Falgueyret JP, Vickers PJ, O'Neill GP Arginine 120 of prostaglandin G/H synthase-1 is required for the inhibition by nonsteroidal anti-inflammatory drugs containing a carboxylic moiety.Journal of Biological Chemistry, 1995;270: 29372-29377.

Mancini JA, Riendeau D, Falgueyret J-P, Vickers PJ, O’Neill GP. Arginine 120 of prostaglandin G/H synthase-1 is required for the inhibition by nonsteroidal anti-inflammatory drugs containing a carboxylic acid moiety. The Journal of Biological Chemistry, 1995;270: 29372-29377.

Mason RP, Walter MF, McNulty HP, Lockwood SF, Byun J, Day CA, Jacob RF. Rofecoxib increases susceptibility of human LDL and membrane lipids to oxidative damage: a mechanism of cardiotoxicity. Journal ofCardiovascular Pharmacology, 2006; 1: S7-14.

Nunthanavanit P,Samee W. Molecular docking of natural productderived compounds: Estimation of selectivity on Cyclo-oxygenase-2. Thai Pharmaceuticaland Health ScienceJournal, 2011;6:79-85.

Orlando BJ. MalkowskiMG.Substrate-selective inhibition of cyclooxygeanse-2 by fenamic acid derivatives is dependent on peroxide tone.The Journal of BiologicalChemistry, 2016; 291: 15069-15081.

Rieke CJ, Mulichak AM, Garavito RM, Smith WL. The role of arginine 120 of human prostaglandin endoperoxide $\mathrm{H}$ synthase- 2 in the interaction with fatty acid substrates and inhibitors. The Journal of Biological Chemistry, 1999;274: 17109-17114.

Selinsky BS. Gupta K. Sharkey CT. LollPJ.Structural analysis of NSAID binding by prostaglandin H2 synthase: time-dependent and timeindependent inhibitors elicit identical enzyme conformations. Biochemistry, 2001; 40: 5172-5180.

Sidhu RS, Lee JY, Yuan C, Smith WL.Comparison of cyclooxygenase-1 crystal structures: Cross-talk between monomers comprising cyclooxygenase-1 homodimers. Biochemistry, 2010; 49: 7069-7079.

Sindhu RS, Lee JY, Yuan C, Smith WL.Comparison of cyclooxygenase-1 crystal structures: Cross-talk between monomers comprising cyclooxygenase-1 homodimers. Biochemistry, 2010; 49: 7069-7079.

Vane JR. Inhibition of prostaglandin synthesis as a mechanism of action for aspirin-like drugs. Nature: New Biology, 1971; 231: 232-235.

Vane JR, Bakhle YS, Botting RM. Cyclooxygenases 1 and 2. Annual Review of Pharmacology and Toxicology, 1998; 38: 97-120.

Vecchio AJ, Simmons DM, Malkowski MG.Structural basis of fatty acid substrate binding to cyclooxygenase-2.Journal of Biology Chemistry, 2010; 285: 22152-22163.

Wong E, Bayly C, Waterman H, Riendeau D, Mancini JA. Conversion of prostaglandin $\mathrm{G} / \mathrm{H}$ synthase- 1 into an enzyme sensitive to PGHS-2-selective inhibitors by a double His513 $\rightarrow$ Arg and Ile523 $\rightarrow$ Val Mutation. The Journal of Biological Chemistry, 1997; 14: 9280-9286.

\section{How to cite this article:}

Levita J, Rositama MR, Alias N, Baderi NK, Saptarini NM, Mutakin M. DiscoveringCOX-2 Inhibitors from Flavonoids and Diterpenoids. J App Pharm Sci, 2017; 7 (07): 103-110. 